\title{
Desde Calímaco a Cervantes: una imagen venatoria en contexto amatorio ${ }^{1}$
}

\author{
José Antonio Bellido DíAZ*
}

Los escritores griegos y latinos acostumbraron a recurrir a las imágenes para describir lo inefable del amor, siempre y cuando pudiera percibirse cierta semejanza entre los ámbitos relacionados por medio de aquellas. Dentro de las imágenes amatorias, tienen cierta repercusión en la literatura clásica las venatorias o cinegéticas ${ }^{2}$.

Entre las múltiples formas que adopta esta imagen, nos vamos a referir a aquella en la que, dentro del contexto del amor rerum difficilium, o deseo por lo difícil, el enamorado se comporta como un cazador que desprecia la pieza conseguida y se afana por perseguir a la que se le escapa ${ }^{3}$.

* Miembro del Grupo de Investigación «Instituto de Estudios Clásicos Nicolaus Heinsius. Edición y comentario» (HUM 261) del Departamento de Filologías Integradas de la Universidad de Huelva.

1. El presente trabajo se ha realizado en el marco del Proyecto de Investigación «Las Metamorfosis de Ovidio» HUM-1019, Proyecto de Excelencia de la Junta de Andalucía 〈http://www.uhu.es/proyectovidio/esp/index.html>.

2. E. J. Kenney, «Doctus Lucretius», Mnemosyne, 23, 1970, 4, pp. 366-393, esp. 386-388; P. Murgatroyd, «Amatory hunting, fishing and fowling», Latomus, 43, 1984, pp. 362-368 C. M. C. Green, «Terms of Venery», TAPhA, 126, 1996, pp. 221-263; J. A. Bellido Díaz, Metáforas amatorias en la elegía latina, Tesis doctoral inédita, Universidad de Huelva, 2003, pp. 203-259.

3. La idea de base de esta imagen venatoria está en las reflexiones sobre la volubilidad de la Fortuna y el carácter del ser humano; magistralmente recogió la idea Plauto (ca. 254-184 a. C.) en Pseudolus, 685 (certa mittimus dum incerta petimus, «dejamos de lado lo que tenemos asegurado, mientras nos ponemos a pretender lo inseguro»). 
$\S 1$. El primero en emplear esta imagen fue Calímaco (310-240 a. C.), Antología Palatina XII $102^{4}$ :

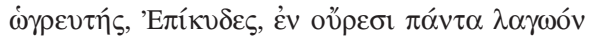

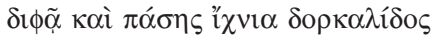

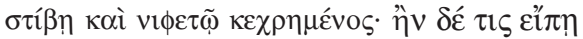

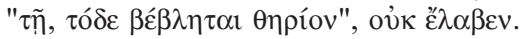

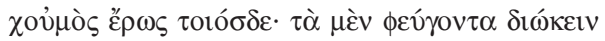

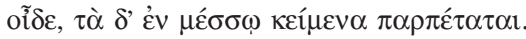

Epicides, acecha el cazador en el monte a la liebre y rastrea las huellas del corzo en medio de la nieve y de la escarcha. Y si alguien le dice «jaquí, una fiera abatida!», no la toma.

Tal es mi amor: persigue lo que huye; lo que yace a su alcance, sobrevuela.

Ya Catulo (ca. 87-ca. 54 a. C.) se hace eco de este pasaje en 8.9-115:

nunc iam illa non uult: tu quoque impotens $<$ noli $>$, nec quae fugit sectare, nec miser uine, sed obstinata mente perfer, obdura.

Ahora ella ya no quiere: tampoco tú quieras, pues no puedes, y no persigas a la que huye de ti, ni vivas desgraciado, sino aguanta con determinación, mantente firme.

Estos dos pasajes se complementan. Por un lado, el pasaje de Calímaco nos ayuda a interpretar correctamente el de Catulo. En efecto, el veronense no emplea en su poema ninguna imagen venatoria que pueda hacernos considerar el v. 9, nec quae fugit sectare, como tal. El poema de Catulo se encuadra dentro de la composión genérica de la renuntiatio amoris o renuncia de amor $^{6}$, y en él Catulo trata de autoconvencerse de no seguir amando a quien le rechaza, y para ello hace recordar al lector culto el poema de Calímaco, a

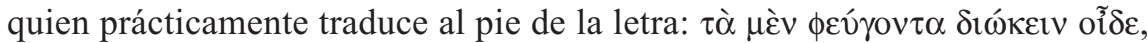
recogiendo tan solo la aplicación amatoria de la imagen del alejandrino. Pero si en Calímaco estamos en contexto venatorio, al lector culto no le queda más remedio que transferir ese contexto al poema catuliano. Claro que la situación es distinta: mientras que Catulo decide no perseguir a la mujer que huye de él, Calímaco, por el contrario, nos dice que prefiere seguir a los jóvenes que huyen de él.

4. Citamos por la edición de Luis Alberto de Cuenca, Calímaco epigramas. Introducción, texto, aparato crítico, traducción y notas, Suplementos de «Estudios Clásicos», n. ${ }^{\circ}$ 6, Eclás, 71, 1974, Callimachi epigrammata $I$.

5. Citamos por la edición de A. Pérez Vega y A. Ramírez de Verger, C. Valerii Catulli carmina. Catulo, poemas, Sevilla-Huelva, Fundación El Monte, 2005, p. 106.

6. Léase a A. Ramírez de Verger, Catulo. Poesías, Madrid, Alianza, 2004 (=1988), p. 149. 
Por otro lado, Catulo nos sirve para interpretar correctamente a Calímaco. Hay quien opina que el Epicides del epigrama es un simple interlocutor del poeta, con quien no le uniría ningún tipo de relación amatoria. Nosotros pen-

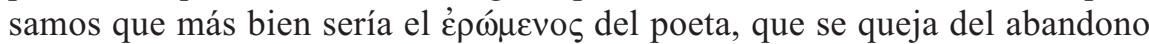
que sufre por parte de Calímaco, quien compone este poema para mostrarle que su comportamiento en el amor es como el del cazador ante las piezas capturadas. Es decir, este epigrama supone una parcial renuntiatio amoris de Epicides, en el afán de su autor por tratar de conseguir el amor de quien le rechaza.

Pero el rechazo de la amada de Catulo no es igual que el rechazo de los pretendidos de Calímaco. Es cierto que en ambos casos ese «rechazo» se indi-

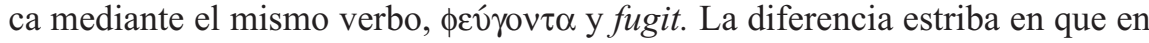
Calímaco ese rechazo no indica ningún tipo de infidelidad, sino un simple desdén hacia el pretendiente, mientras que en Catulo esa 'huida' expresa la infidelidad de Lesbia ${ }^{7}$.

7. Este sentido puede verse en otros pasajes de los elegíacos latinos, como Propercio (ca. 50-ca. 16 a. C.) $2.32 .18-20$ :

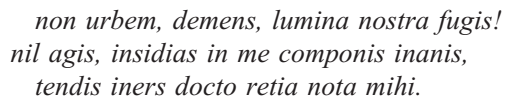

¡No huyes de la ciudad, loca, sino de mis ojos!

No vas a conseguir nada, pues preparas contra mí un cepo inútil, extiendes sin arte unas redes que bien conozco por experiencia.

En efecto, en este poema Propercio describe cómo le invaden las sospechas de infidelidad de su amada a causa de las constantes ausencias de Cintia bien a Tívoli, bien a Lanuvio; de ahí su queja: esas huidas no son más que excusas para su infidelidad, que él bien conoce (acerca de la expresión retia tendere y similares como expresión de la infidelidad, cfr. J. A. BELlido DíAz, Metáforas amatorias en la elegía latina, cit., pp. 219-224). No obstante, la actitud de Propercio respecto a Cintia es totalmente distinta a la de Catulo respecto a Lesbia. Propercio la seguirá amando a pesar de los pesares, le perdonará todos sus deslices, como se hizo con otras mujeres infieles del pasado (vv. 31-36), Helena, la misma Venus, Enone. No cree que deban recibir castigo las mujeres que así se comportan; recuerda que también Lesbia actuó igual que Cintia impunemente (Prop. 2.32.45: haec eadem ante illam impune et Lesbia fecit). Es significativo que precisamente en esta elegía Propercio recuerde a la amada de Catulo; parece querer indicar veladamente que está refiriéndose justamente al poema que estamos comentando del veronés, de quien ha adoptado el término fugere con el sentido de «infidelidad» que evidentemente tiene en ambos poetas.

En otros pasajes elegíacos también aparece el verbo fugere para describir la huida del amante o de la amada: Cat. 37.11 (puella nam mi, quae meo sinu fugit, «Que mi chica, la que huyó de mi lado»; Lesbia huye de Catulo), Cat. 63.80 (Atis de Cíbeles), 64.183-6 (Teseo de Ariadna), Prop. 1.17.1-2 (Et merito, quoniam potui fugisse puellam, / nunc ego desertas alloquor alcyonas, «Y con razón, pues tuve la osadía de huir de mi amada, ahora hablo a las solitarias gaviotas»; Propercio de Cintia), Tibulo (ca. 55-19 a. C.) 1.8.62 (et fugit ex ipso saeua puella toro, «y la cruel muchacha huyó de su propio lecho»; Fóloe de Márato), Prop. 2.30.1-2 (quo fugis, a demens? nulla est fuga: tu licet usque / ad Tanain fugias, usque sequetur Amor, «¿Adónde huyes, insensata? No hay posibilidad de huida: aunque huyas hasta el Don, hasta allí te seguirá Amor»; Cintia de Amor), Prop. 3.12 .31 (et thalamum Aeaeae flentis fugisse puellae, «y haber huido del tálamo de la llorosa joven de Eea»; Ulises de Calipso). Solo insinuamos que en ellos se puede ver una metáfora venatoria, en la que el que huye es la presa que trata de escapar del cazador. 
$\S 2$. El epigrama de Calímaco fue traducido por Horacio (65-8 a. C.) en Sermones (Sátiras) 1.2.105-88:

... leporem uenator ut alta

in niue sectetur, positum sic tangere nolit

cantat et apponit «meus est amor huic similis; nam

transuolat in medio posita et fugientia captat.»

... cómo el cazador persigue a la liebre

en la espesa nieve y a la que se le ofrece no quiere tocarla,

eso canta (el poeta) y añade «mi amor es parecido a esto; pues

sobrevuela lo que se le ofrece y va a cazar lo que huye».

El contexto de la sátira es también amatorio, pero Horacio, aun traduciendo literalmente a Calímaco, recrea la imagen. En efecto, esta parte de la sátira va dirigida a aquellos que pretenciosamente pretenden a mujeres casadas, a ser posible de la nobleza, en lugar de conformarse con amores más fáciles, como el de las prostitutas; con aquellas, en caso de ser descubiertos, sufrirían un castigo, pero con estas perderían la reputación, aunque prefieren aquello a esto (vv. 28-93). Horacio después de emplear varios argumentos intentando convencerles de que se conformen con las mujeres de la segunda clase, termina diciendo que las primeras van vestidas con vestido talar (con lo que pueden ocultar sus defectos), y acercarse a ellas conlleva enfrentarse a muchos obstáculos, como los criados, la litera, los peluqueros, las parásitas, la estola que le llega a los talones (vv. 94-100); en cambio, las segundas casi no ponen ningún obstáculo: sus vestidos de Cos permiten apreciar todo su cuerpo y comprobar los defectos, sin posibilidad de engaño (vv. 101-105). Y ahora es cuando entra en juego el pasaje transcrito, que sería la respuesta del interlocutor de Horacio, al que le confiesa que prefiere lo difícil a lo fácil (vv. 105-108). Pero la advertencia de Horacio no se hace esperar (vv. 109-118): con esos versos que cita del poeta (Calímaco) no va a poder librarse de los dolores y sufrimientos (vv. 109-110); hay que conformarse con el término medio (vv. 111-113); si estuviera sediento, ¿acaso buscaría copas de oro para poder beber? (v. 114); si hambriento, ¿lo rechazaría todo salvo exquisitos manjares? (vv. 115-116); puestos a satisfacer una imperiosa necesidad sexual, ¿preferiría reventar antes que recurrir a una esclava o un esclavo doméstico? (vv. 116-118). Horacio concluye esta argumentación reconociendo que él no actuaría de ese modo, v. 119:

non ego: namque parabilem amo Venerem facilemque.

Yo no: pues amo la Venus asequible y fácil.

Horacio, por tanto, se posiciona en el lado contrario al de Calímaco.

8. Cfr. James E. G. Zetzel, «Dreaming about Quirinus: Horace's Satires and the development of Augustan poetry», Traditions and Contexts in the Poetry of Horace, Cambridge, Cambridge University Press, 2002, pp. 44-45. 
$\S$ 3. Ovidio (43 a. C.-17 d. C.) también se vio tentado por Calímaco 9 a emplear esta imagen en su primera colección de poemas. Así, en Amores 2.9.9-10 podemos leer:

uenator sequitur fugientia, capta relinquit, semper et inuentis ulteriora petit.

El cazador persigue a la presa que huye, deja la cobrada y siempre busca más de lo que encuentra ${ }^{10}$.

Esta elegía que el sulmonense dirige a Cupido como interlocutor también se encuadra, como el poema de Catulo, dentro de una renuntiatio amoris, por lo que no sería atrevido pensar aquí en una doble influencia ${ }^{11}$. Pero este pasaje en particular no se inserta en esa renuntiatio. En efecto, el poeta comienza suplicando a Cupido que deje de asaetearle ${ }^{12}$, más a él que siempre ha cumplido como buen soldado bajo las enseñas del dios del amor (vv. 1-8). Se queja de que Cupido no actúe como los cazadores, que dejan a un lado la pieza cobrada y siguen en busca de la que se les escapa; es decir, en esta imagen el propio poeta representaría la pieza cobrada y Cupido el cazador. En consecuencia, podemos comprobar que Ovidio no copia servilmente a sus predecesores, sino que recrea la imagen dotándola de un nuevo significado: si en los pasajes anteriores la presa era el ser objeto del amor (Epicides, otros mancebos, Lesbia, las matronas o las prostitutas) y el cazador el enamorado (Calímaco, Catulo, los pretendientes de las matronas), ahora en Ovidio la presa pasa a ser el propio enamorado, mientras que el cazador es el mismo dios del amor, Cupido.

En otra elegía de este segundo libro de los Amores (2.19.35-36), en cambio, la situación vuelve a restablecerse:

quidlibet euenuat, nocet indulgentia nobis: quod sequitur, fugio; quod fugit, ipse sequor.

Sea lo que sea, me perjudica la complacencia: huyo de lo que me sigue; sigo a lo que me huye.

En esta elegía Ovidio se queja de que su pretendida no esté suficientemente guardada y pide al necio marido (stultus uir) una estricta vigilancia (vv. 1-8); es más, pocos versos más adelante, indica a su amada que ella misma debe ponerle obstáculos a sus requerimientos para que así su amor hacia ella crezca

9. Sobre la influencia de Calímaco en Ovidio, puede verse MARIA DE COLA, Callimacho e Ovidio, Palermo, Trimarchi, 1937.

10. Citamos el texto latino por la edición de A. Ramírez de Verger, Carmina amatoria, Stuttgart-Leipzig, Franz Steiner, 2003. La traducción es de A. RAmírez DE Verger, Ovidio, Amores, Madrid, Alianza, 2001. Lo mismo vale para el siguiente pasaje de Ovidio.

11. Sobre la influencia de Catulo en Ovidio, puede leerse a J. FERGuson, «Catullus and Ovid», AJPh, 81, 1960, 4, pp. 337-357.

12. La imagen de Cupido lanzado sus dardos contra los enamorados es una metáfora del enamoramiento; la petición de que ceje en sus ataques es metáfora de la renuntiatio amoris. 
(vv. 19-34). En este contexto inserta Ovidio el dístico que nos ocupa. De nuevo el poeta hace trabajar al lector haciéndole recordar no ya solo el pasaje de Calímaco $^{13}$, sino también el de los poetas latinos que le imitaron. Puede comprobarse que la situación ahora es la misma que veíamos anteriormente: el cazador vuelve a ser el enamorado, y la presa objeto de su cacería, la amada.

$\S$ 4. Demos un salto cronológico hasta Cervantes. En una de sus Novelas ejemplares, La gitanilla, el caballero Andrés se ha enamorado de la protagonista, Preciosa, y para conseguir su amor ha decidido renunciar a su condición y amoldarse a las costumbres de los gitanos, en prueba de su sinceridad; los gitanos mayores deciden permitir las relaciones del joven con Preciosa, pero esta, antes de dar su consentimiento, prefiere poner una serie de condiciones a su pretendiente ${ }^{14}$.

Porque a mi parecer los ímpetus amorosos corren a rienda suelta, hasta que encuentran con la razón o con el desengaño, y no querría yo que fueses tú para conmigo como es el cazador, que en alcanzando la liebre que sigue, la coge, y la deja por correr tras otra que le huye.

Que es evidente que tenemos aquí la misma imagen de Calímaco, con algunas modificaciones, a nadie se le escapa. Además, se aplica también a un contexto amatorio. La principal innovación es que se pone en boca de una mujer, Preciosa, cuando en los casos anteriores siempre era un varón el que la utilizaba. Podríamos añadir que Cervantes pretende dar la impresión de que esta imagen no pertenece por exclusivo al ámbito culto de los conocedores de la literatura (los propios escritores, como sucedía hasta el momento: Calímaco, Catulo, Ovidio y Horacio expresan esta imagen por su propia boca), sino que la inserta en el discurso de Pre-

13. En opinión de W. G. HARDy, «On Ovid Am. II 19 and III 14», Classical Philology, 18, 1923, 3 , pp. 263-264, el tema principal de esta elegía (poner vigilancia a la amada) está más en relación con

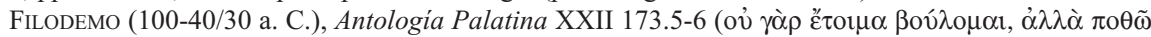

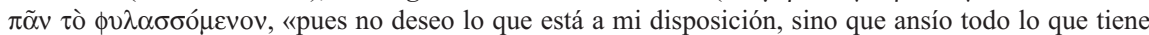
vigilancia»), que con CALímACO, Antología Palatina XXII 102.5-6. La influencia de Filodemo no puede ponerse en duda, sobre todo respecto al comienzo de la elegía, vv. 1-3:

\footnotetext{
Si tibi non opus est seruata, stulte, puella, at mihi fac serues, quo magis ipse uelim. quod licet, ingratum est; quod non licet, acrius urit:

Si no sientes, estúpido, necesidad de vigilar a tu mujer, ¡al menos procura vigilarla por mí, para que yo la desee más!

Lo que está permitido no tiene encanto; lo que no, abrasa más.
}

Ahora bien, estamos convencidos de que Ovidio tiene en mente, sin duda, también el poema de Calímaco. Véase, en este sentido, P. Murgatroyd, «Amatory hunting, fishing and fowling», cit., p. 366.

14. Citamos por la primera edición de las Novelas ejemplares, dada en Madrid por Juan de la Cuesta en 1613. Hemos adaptado la ortografía y la puntuación a las normas actuales. Esta edición puede seguirse en la siguiente dirección de Internet: 〈http://www.cervantesvirtual.com/FichaObra.html? Ref $=4980 \&$ portal $=40$. 
ciosa con una naturalidad tal que induce al lector a pensar que más bien pertenece al acerbo cultural del pueblo llano, a la sabiduría popular, como uno más de los refranes, adagios y comparaciones tradicionales ${ }^{15}$. Ahora bien, mantiene el mismo sentido que tenía: el enamorado se comporta con la amada como el cazador con la pieza cobrada, a la que abandona para ir en busca de otra que se le escapa. Pero Preciosa no está pensando tanto en que el hombre prefiere los amores difíciles, cuanto en que el amor masculino es tornadizo y proclive a la infidelidad y a la transitoriedad. No se le escapa tampoco a Preciosa el carácter voluble del hombre, que, minusvalorando lo conseguido, ansía por naturaleza lo que huye de él dentro de su característico amor rerum difficilium, manteniendo la imagen, de este modo, el sentido original que le confirió Calímaco.

$\S 5$. La cuestión que se plantea es cuál sería la fuente de Cervantes. No debe negársele al genio de Alcalá cierto conocimiento de la lengua latina (maestro suyo fue el humanista López de Hoyos, 1511-1583, con quien sin duda leería algún pasaje de la obra de Ovidio o de Horacio), y no sería descartable una influencia directa. Pero dada la ausencia de datos irrevocables, pensamos que es más probable que tuviera conocimiento de esta imagen clásica de manera indirecta, a través de Ludovico Ariosto (1474-1533) ${ }^{16}$, quien en su Orlando furioso, canto 10 , estrofa 7 , dice lo siguiente:

Guardatevi da questi che sul fiore

de' lor begli anni il viso han si polito;

che presto nasce in loro e presto muore,

quasi un foco di paglia, ogni appetito.

Come segue la lepre il cacciatore

al freddo, al caldo, alla montagna, al lito,

né più l'estima poi che presa vede;

e sol dietro a chi fugge affretta il piede ${ }^{17}$.

15. Como se sabe, en realidad Preciosa es una muchacha de origen noble, cuyo verdadero nombre es Constanza, que fue robada, siendo niña, por la familia gitana con la que convive. Se ha notado que el comportamiento noble que demuestra Preciosa a lo largo de la novela no está conforme con el ambiente en que vive; no debemos olvidar que en la época de Cervantes estaba en vigor la idea de que la nobleza de espíritu procede de la nobleza de sangre. Sin embargo, ello no obsta para que Preciosa se haya amoldado a las costumbres gitanas y haya asumido su idiosincrasia. Con esto queremos decir que la imagen que utiliza Preciosa no debemos considerarla exclusiva de un lenguaje elevado, sino que más bien es patrimonio del pueblo (de otro modo, Cervantes habría ido en contra de la verosimilitud, que es precisamente su característica literaria más reconocida). Véase F. RAHUT, «Consideraciones sociológicas sobre la "Gitanilla" y otras "novelas" cervantinas», Anales Cervantinos, 3, 1953, pp. 145-160.

16. En su estudio «La biblioteca de Cervantes: una reconstrucción», versión preliminar de 2002 $<\mathrm{http} / /$ bigfoot.com/ daniel.eisenberg $>$, Daniel Eisenberg indica que Cervantes debió poseer alguna edición del Orlando furioso de ARIosto en italiano, y también la traducción que de ella hizo en 1549 Jerónimo de Urrea (1513-a. 1574), que conoció doce ediciones desde 1553 a 1587-1588 (Urrea es el «señor capitán» traductor de ARIOSTO a quien se refiere en Don Quijote I, 6.) Para los vínculos entre Ariosto y Cervantes, vid. TH. Hart, Ariosto and Cervantes: Renewing Fiction, Princeton, Princeton University Press, 1989; M. S. BrownleE, «Cervantes as Reader of Ariosto», Romance. Generic Tranformation from Chrétien de Troyes to Cervantes, K. Brownlee y M. S. BrownleE (eds.), Hanover, UP of New England, 1985, pp. 220-237.

17. Jerónimo de Urrea tradujo así, canto 9, estrofa 7 (en el canto 9, pues Urrea suprimió el canto 2 del original, que incluía una larga profecía de Melisa con la glorificación de la familia Este, para uno de 
En este canto 10, Ariosto va a narrar el pérfido abandono de Olimpia por parte de Bireno (estrofas 1-34) ${ }^{18}$; este la lleva en su barco para casarla con un primo suyo, pero durante el viaje «e riputato avria cortesia sciocca, / per darla altrui, levarsela di bocca» (Urrea: «piensa que es cortesía más que loca / quitarla para otro de su boca»), por lo que se detiene durante la travesía en una isla donde goza de la joven y, tras zarpar, la abandona allí.

Las primeras estrofas de este canto son introductorias para la escena del abandono y en ellas Ariosto enseña a las mujeres, a las que trata como interlocutoras, a no dejarse convencer por los jóvenes pretendientes: él nunca ha visto un amor más fiel que el de Olimpia (estrofa 1); Bireno debería corresponder con idéntico amor a Olimpia (estrofa 2); no debería olvidarla ni aunque la mismísima Helena de Troya se cruzara en su camino (estrofa 3); pero él se comportó pérfidamente con la muchacha, como va a contar ahora (estrofa 4); la mujer no debe creer en las promesas y juramentos de los hombres, que los hacen solo por conseguir su deseo (estrofa 5); no deben ceder las jóvenes a esos juramentos vanos, y como ejemplo les pondrá la historia de Olimpia (estrofa 6).

Ya en la estrofa 7, arriba reproducida, les sugiere guardarse de los jóvenes de bello rostro, pues en ellos surge raudo el deseo e igual de raudo muere: son como el cazador que alcanza la liebre y echa a correr tras otra que le huye. La imagen de Ariosto está desarrollada en los mismos términos que la de Calímaco y Horacio, más, por tanto, que en Catulo y Ovidio. En efecto, solo Calímaco y Horacio mencionaban las dificultades que representa para el cazador la

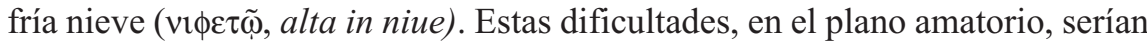
las negativas de la dama a las pretensiones del enamorado: por ello, Ariosto aconseja en la estrofa siguiente, la octava, que ellas deben mostrar desdén y

cuyos miembros, el cardenal Hipólito, Ariosto escribe su poema; Urrea fundió los cantos 2 y 3 , con lo que su traducción contiene un total de 45 , frente a los 46 del original; citamos por la edición que de esta traducción hizo Francisco José Alcántara en Ludovico Ariosto, Orlando furioso, Barcelona, Planeta, 1988, p. 125):

\footnotetext{
Guardaos de estos que veis en flor de vida, con un rostro gentil de amor vencido que presto en ellos nace y veis perdida, $\mathrm{y}$ es humo su apetito mal regido.

Son como el cazador que trae seguida liebre, que al hielo y sol bien la ha corrido, y presa, como cosa vil desprecia, y sólo a quien le huye quiere y precia.
}

18. La influencia de Catulo 64.52-264 y de Ovidio Heroidas 10 (Ariadna abandonada por Teseo) en este pasaje es más que evidente. Cfr. D. JAVITCH, «The Imitation of Imitations in Orlando Furioso», Renaissance Quarterly, 38, 1985, 2, pp. 215-239, donde podrá leerse un análisis de las relaciones entre estos textos con bibliografía de los estudiosos que las han investigado. Así, por ejemplo, ya Lodovico Dolce (1508-1568) las había observado en un apéndice a la edición de 1542 del Orlando Furioso en Venecia, y reimpreso en las más de veintiocho ediciones que publicó Giolito entre 1542 y 1560, además de en otras de mediados del siglo. Véase también D. JAVITCH, «Sixteenth-Century Commentaries on Imitations in the Orlando Furioso», Harvard Library Bulletin, 34, 1986, pp. 221-250. 
aspereza para mantener vivo el amor de los jóvenes, pues en el caso de ceder, enseguida mudarán su amor ${ }^{19}$.

Pero, frente a los poetas anteriores, confiere a la imagen una nueva perspectiva: sirve no ya solo para expresar el carácter voluble de los hombres, sino, sobre todo, su tendencia a la infidelidad; precisamente este era el aspecto que le interesaba resaltar a la Preciosa de Cervantes cuando advertía a su pretendiente Andrés.

$\S 6$. Hagamos un resumen con las características que presentan los autores referidos en el uso de esta imagen iniciado por Calímaco.

a) Calímaco. Presenta dos partes, la venatoria propiamente dicha (vv. 1-4) y su aplicación amatoria (5-6). La aplicación amatoria contiene una metáfora que ha sido favorecida (lo que nosotros denominamos «metáfora anunciada») por la comparación con la imagen precedente. Con ella, el poeta expresa el amor rerum difficilium y al mismo tiempo una renuntiatio del amor conseguido (Epicides), que se considera fácil.

b) Catulo. Metáfora pura, sin anuncio previo a través de la imagen venatoria, que está ausente, pero obliga al lector a tenerla presente para comprender correctamente el pasaje. No expresa el amor rerum difficilium sino tan solo la renuntiatio, aunque no del amor conseguido, mas de quien le rehúye (Lesbia). Está en boca del propio poeta.

c) Horacio: presenta las dos partes de Calímaco, la venatoria y la amatoria. La imagen no se inserta en un poema como parte de él, sino que tiene entidad propia, empleada por el interlocutor del poeta como una especie de adagio para expresar su preferencia por el amor difícil (el adúltero), frente al amor fá-

19. Canto 10, estrofa 8:

$$
\begin{aligned}
& \text { così fan questi gioveni, che tanto } \\
& \text { che vi mostrate lor dure e proterve, } \\
& \text { v'amano e riveriscono con quanto } \\
& \text { tudio de' far chi fedelmente serve; } \\
& \text { ma non sì tosto si potran dar vanto } \\
& \text { de la vittoria, che, si donne, serve } \\
& \text { vi dorrete esser fatte; e da voi tolto } \\
& \text { vedrete il falso amore, e altrove volto. }
\end{aligned}
$$

Que Jerónimo de Urrea traduce así:

$$
\begin{aligned}
& \text { Así son estos mozos que, entretanto } \\
& \text { que les mostráis desdén y aun aspereza, } \\
& \text { os aman y respetan todo cuanto } \\
& \text { es posible a quien ama con firmeza. } \\
& \text { Mas no tan presto de victoria un tanto } \\
& \text { gozarán: que queréis ser con tristeza } \\
& \text { de señoras, esclavas, y quitado } \\
& \text { veréis su amor, y en otras tal mudado. }
\end{aligned}
$$


cil de las prostitutas. No hay renuncia de una persona en particular, sino de un tipo de amor.

d) Ovidio, Am. 2.9.9-10. Solo se emplea la parte venatoria de la imagen, que se presenta en forma de sentencia para concluir un argumento previo, dentro de la súplica a Cupido de que deje de lanzarle dardos. Está en boca del propio poeta. En realidad, se oculta una renuntiatio al amor en general. No existe una confrontación entre el amor fácil y el deseo por lo difícil.

e) Ovidio, Am. 2.19.35-6. Se emplea solo la parte amatoria (metáfora pura), haciendo al lector recordar el contexto venatorio. Realmente no existe una renuncia a la amada, sino a lo sumo una velada amenaza que sirve como recomendación de que se le haga difícil su acceso, para que así crezca y perdure el amor en él; el amor conseguido se abandona como el cazador a la pieza cobrada. Expresa, pues, el amor rerum difficilium.

f) Cervantes. Se emplea la imagen como corolario de carácter gnómico de una argumentación acerca de la inconstancia e infidelidad de los varones una vez conseguido el objeto de amor (orden inverso). Se presenta bajo la forma de comparación. Expresa que el amor rerum difficilium sirve para conservar el amor. Está en boca de la protagonista, no del autor.

g) Ariosto. Aparecen tanto el plano amatorio (X 7.1-4), como el venatorio (X 7.5-8), en orden inverso al de Calímaco. Sirve para expresar la inconstancia e infidelidad del amante masculino, también como corolario de una argumentación anterior que arranca ya desde la primera estrofa de este canto. Aunque se prolonga la argumentación a la estrofa siguiente, para enseñar a las mujeres que deben poner obstáculos en el amor con el fin de hacerlo perdurable. Está en boca del autor.

Comparando solo estos últimos apartados, resulta evidente que Cervantes tomó directamente de Ariosto esta imagen venatoria.

Recibido: 22-3-2007

Aceptado: 4-4-2008

\section{Resumen}

La imagen del cazador que persigue la presa que huye y deja la que atrapa, dentro de un contexto amatorio (el enamorado es el cazador que persigue a la amada huidiza, abandonando a la que ya ha conseguido), se inicia con Calímaco y llega hasta Cervantes, quien la tomaría no de las fuentes clásicas, sino del Orlando Furioso de Ariosto. La imagen adquiere diversas aplicaciones, según los autores que la utilizan.

Palabras clave: Metáfora amatoria. Motivos amatorios. Cacería. Amor. Calímaco. Catulo. Ovidio. Horacio. Cervantes. Ariosto. Gitanilla. Orlando Furioso. Renuntiatio amoris. Amor rerum difficilium. 
Title: From Calimaco to Cervantes: a hunting image in a love context

\begin{abstract}
The image of the hunter going after the escaping prey and scorning that one caught, in an amatory context (the lover is the hunter going after the escaping beloved, leaving the woman he has already conquered), starts from Callimachus and goes to Cervantes, who probably should take it not from classical sources, but from Ariosto's Orlando Furioso. The image offers different applications, depending on the authors who employ it.
\end{abstract}

Key words: Amatory metaphor. Amatory motive. Hunting. Love. Callimachus. Catullus. Ovid. Horace. Cervantes. Ariosto. Gitanilla. Orlando Furioso. Renuntiatio amoris. Amor rerum difficilium. 